\title{
INJÚRIA POTENCIAL DE HERBICIDAS DE SOLO AO GIRASSOL. II - Chlorimuron-ethyl ${ }^{1}$
}

\author{
NILSON G. FLECK ${ }^{2}$ e RIBAS A. VIDAL ${ }^{3}$
}

\begin{abstract}
RESUMO
Conduziu-se um ensaio de campo na Estação Experimental Agronômica da Universidade Federal do Rio Grande do Sul, em Eldorado do Sul, RS, em 1989/90. O objetivo do trabalho foi determinar o efeito residual potencial do herbicida chlorimuron-ethyl, aplicado em três doses à superfície do solo (PRE) ou incorporado no mesmo (PPI), sobre a cultura de girassol. A atividade de chlorimuron-ethyl (etil 2(((((4-cloro-6-metoxipirimidina $\quad-2$ il)amino)carbonil) amino)sulfonil)benzoato) não foi dependente de sua posição no solo. Chlorimuron-ethyl promoveu injúria inicial acentuada, constatando-se pouca ou nenhuma resposta ao

aumento da dose para matéria seca da parte aérea do girassol, área foliar e estatura das plântulas. Contudo, avaliação de estatura das plantas, realizada na maturação fisiológica, indicou que os danos promovidos pelo herbicida reduziram-se com o decorrer do tempo. Concluiu-se que, aparentemente, num sistema de sucessão soja-girassol, o efeito residual potencial de chlorimuron-ethyl ao girassol é pequeno.

Palavras-chave: Helianthus annuus, herbicidas residuais, dissipação de herbicidas, persistência no solo, rotação de culturas, sulfoniluréias.
\end{abstract}

\section{ABSTRACT \\ Potential sunflower injury by soil applied herbicides. II - Chlorimuron-ethyl}

A field experiment was carried out during 1989/90 at the Eldorado do Sul Experimental Station of Federal University of "Rio Grande do Sul", Brazil with the objective of evaluating potential injury to sunflower by chlorimuronethyl applied at three different dosages in pre-emergence (PRE) or preplant incorporated (PPI).

Chlorimuron-ethyl activity was not dependent on the application method. Early in the season there were higher levels of injury to the plants, with little or no response to

\section{INTRODUÇÃO}

Chlorimuron-ethyl (etil 2-((((4-cloro-6-metoxipirimidina-2 il)amino)carbonil)amino)sulfonil)benzoato) é

1 Recebido para publicação em 06/04/93 e na forma revisada em 10/12/93. Extraído da Dissertação apresentada pelo segundo autor para obtenção do grau de Mestre em Fitotecnia pela Fac. de Agron. da Univ. Fed. do Rio Grande do Su1 (UFRS), Porto Alegre, RS. Trabalho parcialmente financiado pelo CNPq (Processo ${ }^{\circ}$ 414024/89-31AG).

2 Eng $^{\circ}$.- Agr ${ }^{\circ}$., Ph. D., Prof. Adjunto, Dep. de Plantas de Lavoura da UFRS/Fac. de Agron., Av. Bento Gonçalves, 7712, Caixa Postal 776, CEP 90001-970, Porto Alegre, RS. Bolsista do CNPq.

3 Eng..- Agr ${ }^{\circ}$., MSc., Prof. Assistente, Dep. de Plantas de Lavoura da UFRS/Faculdade de Agronomia dosages with regard to shoot weight, leaf area and seedling size. However, plant height assessed late in the season indicated recovery from initial symptoms. Apparently, chlorimuron-ethyl injury to sunflower is limited in a rotation soybean-sunflower.

Additional index words: Helianthus annuus, residual herbicide, herbicide dissipation, soil persistence, crop rotation, sulfonylureas.

um herbicida seletivo recomendado para controle de plantas daninhas dicotiledôneas na cultura da soja. Este produto pertence ao grupo químico das sulfoniluréias, o qual, embora recentemente descoberto, apresentava cerca de 230 compostos patenteados por 14 empresas em 1987 (Beyer et al., 1988). O modo de ação dos produtos deste grupo químico consiste na inibição competitiva da enzima acetohid roxiácido sintase (AHAS), também conhecida como acetolactato sintase (ALS) (EC 4.1.3.18), a qual catalisa as reações de síntese dos aminoácidos valina, leucina e isoleucina (Mazur \& Falco, 1989). A redução dos níveis destes aminoácidos acarreta sérios distúrbios na produção de proteína celular, interferindo no crescimento celular, promovendo necrose no 
meristema apical e paralisação do crescimento do mesmo (Ray, 1984; Mazur \& Falco, 1989).

Como a ALS é relativamente sensível às sulfoniluréias, os herbicidas deste grupo químico são eficazes em doses que variam entre 1 e $100 \mathrm{~g} / \mathrm{ha}$. Este fato explica o problema de sua persistência para culturas sensíveis (Brewster \& Appleby, 1983; Peterson \& Arnold, 1985). 0 herbicida clorsulfuron, por exemplo, pertencente a este grupo químico, é 1000 vezes mais ativo em beterraba do que em trigo. Assim, resíduos relativamente reduzidos deste composto no solo poderão causar injúria à cultura de beterraba se cultivada em rotação ao trigo (Brewster \& Appleby, 1983; Beyer et al., 1988). No caso de chlorimuron-ethyl (doravante denominado apenas chlorimuron), a recomendação do rótulo é de que se deixe um intervalo de pelo menos 120 dias entre a aplicação do produto e a semeadura de culturas tais como trigo ou milho em rotação com soja. Existe, ainda, a indicação de que sejam realizados bioensaios antes da semeadura de outras culturas na rotação com a soja.

A persistência das sulfoniluréias no solo é afetada principalmente pela decomposição química, decomposição pelas plantas e microorganismos e adsorção aos colóides do solo (Beckie \& Mckercher, 1989). Estes autores constataram que sob $\mathrm{pH}$ baixo $(5,5$ a 6,9$)$, a persistência das sulfoniluréias era menor do que sob pH elevado $(7,6$ e 8,1), sendo atribuída degradação via hidrólise mais acentuada no primeiro caso. A ocorrência de maior degradação das sulfoniluréias em solo não esterilizado, comparado aos solos esterilizados, observada por Beckie \& Mckercher (1989), foi atribuída à degradação microbiana. De fato, Beyer et al. (1988) relataram que microorganismos do solo, tais como os dos gêneros Aspergilus e Penicillium, eram os responsáveis pela degradação. Goetz et al. (1989), por sua vez, verificaram que a adsorção de chlorimuron era acentuada em solos que continham proporções relativamente altas das argilas hematita e gibsita.

Estudos de laboratório indicaram que sob temperatura de $5^{\circ} \mathrm{C}$ a meia-vida do chlorimuron era de 40 semanas (Beyer et al., 1988). Já trabalhos de campo, realizados por Curran \& Knake (1987), indicaram reduções do peso de matéria seca e da estatura de plântulas de milho cuja semeadura foi feita 1 ano após a aplicação de chlorimuron. Segundo os mesmos autores, em solos com $\mathrm{pH}$ elevado as reduções de crescimento persistiram até o final do ciclo, embora não tenham afetado significativamente a produtividade do milho.

Não se tem informações detalhadas sobre a persistência e os efeitos do chlorimuron para a cultura do girassol, que no Rio Grande do Sul chega a ser semeado 210 dias após a implantação da soja. Portanto, objetivourse com este trabalho determinar o efeito residual potencial de chlorimuron sobre a cultura do girassol sob condições locais.

\section{MATERIAL E MÉTODOS}

Um experimento foi conduzido em campo durante a estação de crescimento de 1989/90, na Estação Experimental Agronômica (EEA) da Universidade Federal do Rio Grande do Sul (UFRS), localizada no município de Eldorado do Sul, RS, região fisiográfica da Depressão Central do Estado.
O delineamento experimental utilizado foi o de blocos casualizados, arranjados em parcelas subdivididas, com quatro repetições. Cada bloco foi composto de duas parcelas às quais foram destinadas as épocas de aplicação dos herbicidas (pré-plantio incorporado - PPI, e pre-emergência - PRE). Cada parcela foi dividida em 12 unidades experimentais (subparcelas), nas quais foram aplicados, de forma aleatória, os tratamentos herbicidas. A área total da parcela foi de 120 $\mathrm{m}^{2}$ (4 x 30m); a da subparcela foi de $10 \mathrm{~m}^{2}$ (2,5 x 4m), com uma área útil central de $4,5 \mathrm{~m}^{2}(1,5 \times 3 \mathrm{~m})$. A cada bloco acrescentou-se uma área extra de $10 \mathrm{~m}^{2}(2,5$ x 4m) destinada à testemunha não tratada com herbicida de solo. Cada repetição apresentou, portanto, 25 unidades experimentais (subparcelas).

Em cada época de aplicação (parcela) os tratamentos foram organizados num esquema fatorial hierárquico, isto é, foram utilizados quatro herbicidas (clomazone, chlorimuron, imazaquin e imazethapyr), cada um deles aplicado em três doses, que corresponderam àquelas usuais, metade e um décimo daquelas recomendadas pela pesquisa para utilização em soja. Esse delineamento experimental permite que se apresentem aqui apenas os resultados do herbicida chlorimuron, o qual foi aplicado nas doses de 50, 25 e $5 \mathrm{~g} / \mathrm{ha}$, no dia 29/08/89.

As informações pertinentes ao tipo de solo, seu preparo e adubação, aplicações herbicidas, semeadura do girassol e tratos culturais praticados foram as descritas por Vidal \& Fleck (1993).

Durante os 40 dias após a aplicação dos herbicidas ocorreram precipitações pluviométricas da ordem de $270 \mathrm{~mm}$, distribuídas em 16 dias.

As avaliações realizadas foram matéria seca da parte aérea e do sistema radicular do girassol, estatura das plantas e área foliar. Estas determinações foram realizadas sobre uma amostra de seis plantas por parcela, coletadas aos 31 dias após a aplicação dos tratamentos (DAT), correspondentes a 21 dias após a emergência da cultura do girassol. As plântulas foram coletadas com o auxílio de uma pá e lavadas no momento da coleta, para se fazer a separação do sistema radicular e do solo. A área foliar foi avaliada atravéz de equipamento munido de câmera ótica de varredura. A matéria seca foi determinada com balança analítica, após a secagem do material em estufa com circulação de ar à $60^{\circ} \mathrm{C}$. A relação parte aérea/sistema radicular foi obtida à partir dos dados de ambas matérias secas. Aos 110 dias após a semeadura, quando as plantas se encontravam no início da maturação fisiológica, determinou-se a estatura média do girassol, avaliando-se 10 plantas por parcela.

As variáveis avaliadas no experimento foram submetidas à análise de variância de acordo com o modelo de parcelas subdivididas. Quando constatada a significância de dose para o herbicida chlorimuron ou da interação época/dose de chlorimuron, procedeu-se ao desdobramento dos graus de liberdade correspondentes, utilizando-se a análise de regressão, testando-se a significância da regressão linear e desvios da mesma. Os coeficientes polinomiais ortogonais foram calculados através do método para níveis não-equidistantes, desenvolvido por Nogueira (1979). Determinaram-se as equações lineares significativas e, caso o quadrado médio 
dos desvios de uma regressão fosse significativo, utilizou-se o procedimento apresentado por Gomez \& Gomez (1984).

Cada dose de herbicida foi comparada à testemunha (sem aplicação) através do teste DMS, ao nível de 5\% de probabilidade. Optou-se pela utilização do teste DMS, neste experimento, principalmente para comparar a testemunha com a menor dose testada, uma vez que a análise de regressão já é suficiente para a comparação entre doses (Chew, 1976 e Petersen, 1977).

\section{RESULTADOS E DISCUSSÃO}

Os resultados da análise de varíância para avaliações nas plantas de girassol não apresentaram interação do modo de aplicação e doses de chlorimuron, indicando que o efeito do produto não foi dependente do método de aplicação ao solo. Dessa forma, representou-se graficamente o efeito médio dos modos de aplicação testados (Figuras 1 a 3).

Observou-se redução da área foliar e da matéria seca da parte aérea das plântulas com o aumento da dose de chlorimuron (Figura 1). As plântulas que se desenvolveram em área tratada já coma menor dose deste composto mostraram menores área foliar e matéria seca do que as da testemunha.

A estatura das plantas, em quaisquer das duas épocas de avaliação, não foi influenciada pelo incremento da dose de chlorimuron (Figura 2). Comparando-se as plantas da testemunha com as da menor dose de chlorimuron, detectou-se redução significativa da estatura na avaliação realizada aos 31 DAT. Contudo, na avaliação realizada aos 110 DAT tal diferença já não era observada.

Com incremento da dose, chlorimuron promoveu redução da relação parte aérea/raiz, sendo que esta redução foi muito acentuada mesmo na menor dose. Isto significa que,

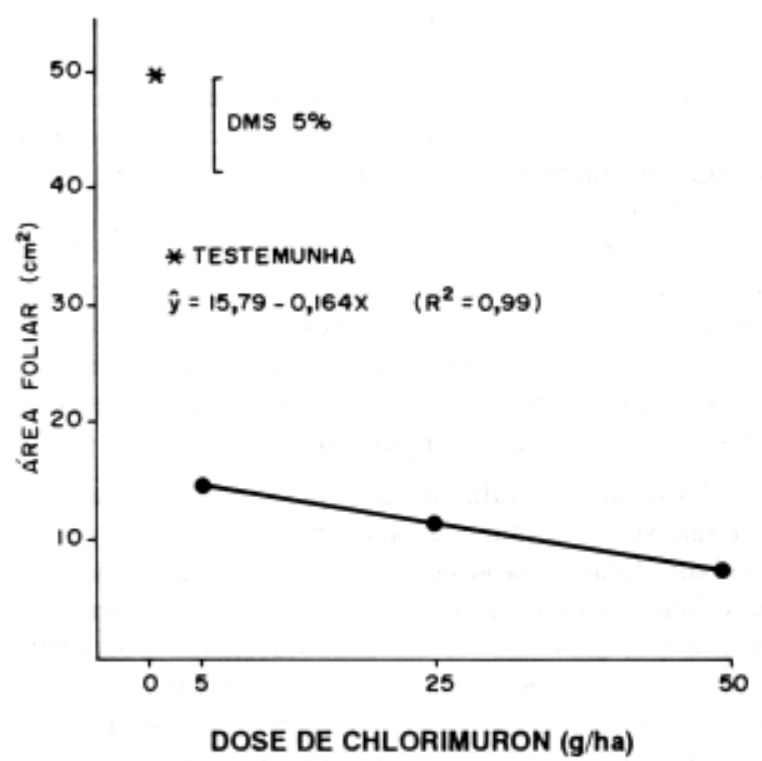

com o incremento da dose, ele afetou mais drasticamente a parte aérea do que a parte radicular das plantas (Figura 3).

Os resultados indicaram que o efeito do produto sobre girassol não foi dependente do modo de aplicação ao solo. Estes resultados coincidem com os obtidos por Wesley et al. (1989), que não constataram diferenças no desempenho deste herbicida, quando aplicado em PPI e PRE no controle de diversas espécies daninhas. Os autores atribuíram este resultado à ocorrência de precipitação pluvial acentuada após a aspersão do herbicida. De fato, neste trabalho também ocorreram precipitações acentuadas até 40 dias após a aplicação, as quais devem ter distribuído o herbicida no perfil do solo. Além disto, a distribuição do herbicida através do perfil do solo pode ter reduzido sua fotodecomposição (Thomas \& Harrison, 1990; Harrison \& Thomas, 1990).

Chlorimuron foi muito fitotóxico na avaliação aos 31 DAT, tendo sido constatada redução acentuada na área foliar, matéria seca da parte aérea e estatura das plantas de gírassol (Figuras 1 e 2). No entanto, houve pouca ou nenhuma resposta destes parâmetros com o incremento da dose. Estes fatos podem ser explicados por uma ou mais das três hipóteses seguintes. Primeira, a possibilidade de que a absorção deste composto tenha sido pouco influenciada pelos diversos fatores inerentes ao ambiente, apesar de o produto apresentar algumas características que dificultam sua difusão no solo, tais como peso molecular de 415 (que é indicativo de tamanho molecular relativamente acentuado) e baixa dose e grande diluição no solo (Schmidt \& Pestemer, 1980). Segunda, a possibilidade de que a translocação deste composto tenha sido eficiente (Beyer et al., 1988). E terceira, a possibilidade de que as isozimas de ALS presentes no híbrido de girassol DK 180 sejam sensíveis ao chlorimuron.

Constatou-se efeito mais pronunciado de chlorimuron na parte aérea do que no sistema radicular do girassol, quando avaliado aos 31 DAT (Figura 3). As três explicações pos-

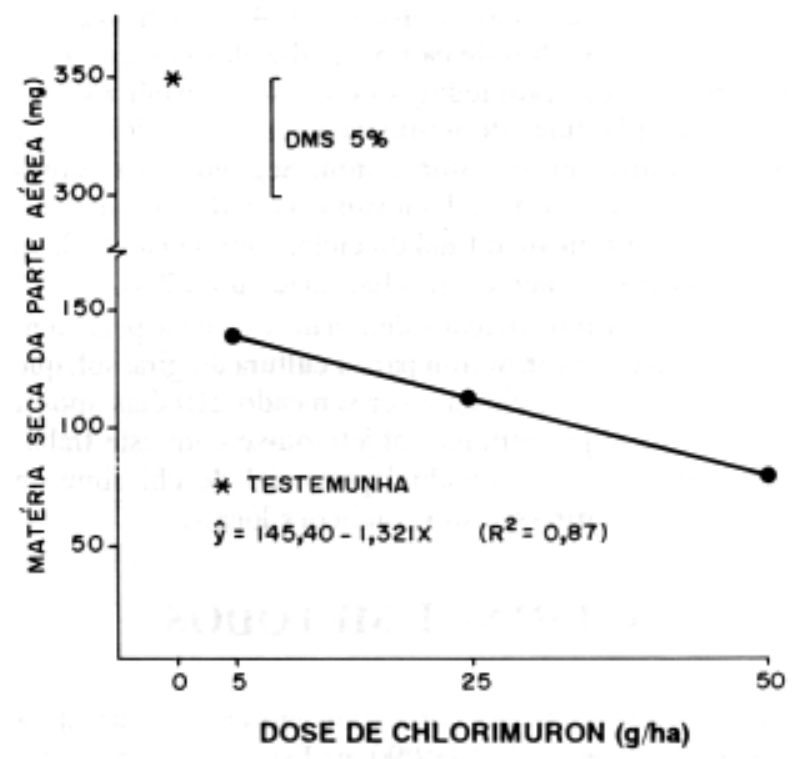

FIG. 1. Área foliar e matéria seca da parte aérea das plantas de girassol aos 31 dias após aspersão ao solo do herbicida chlorimuron (média das aplicaçōes em PRE e PPI), comparadas à testemunha sem herbicida. EEA/UFRS, Eldorado do Sul, RS, 1989/90. 

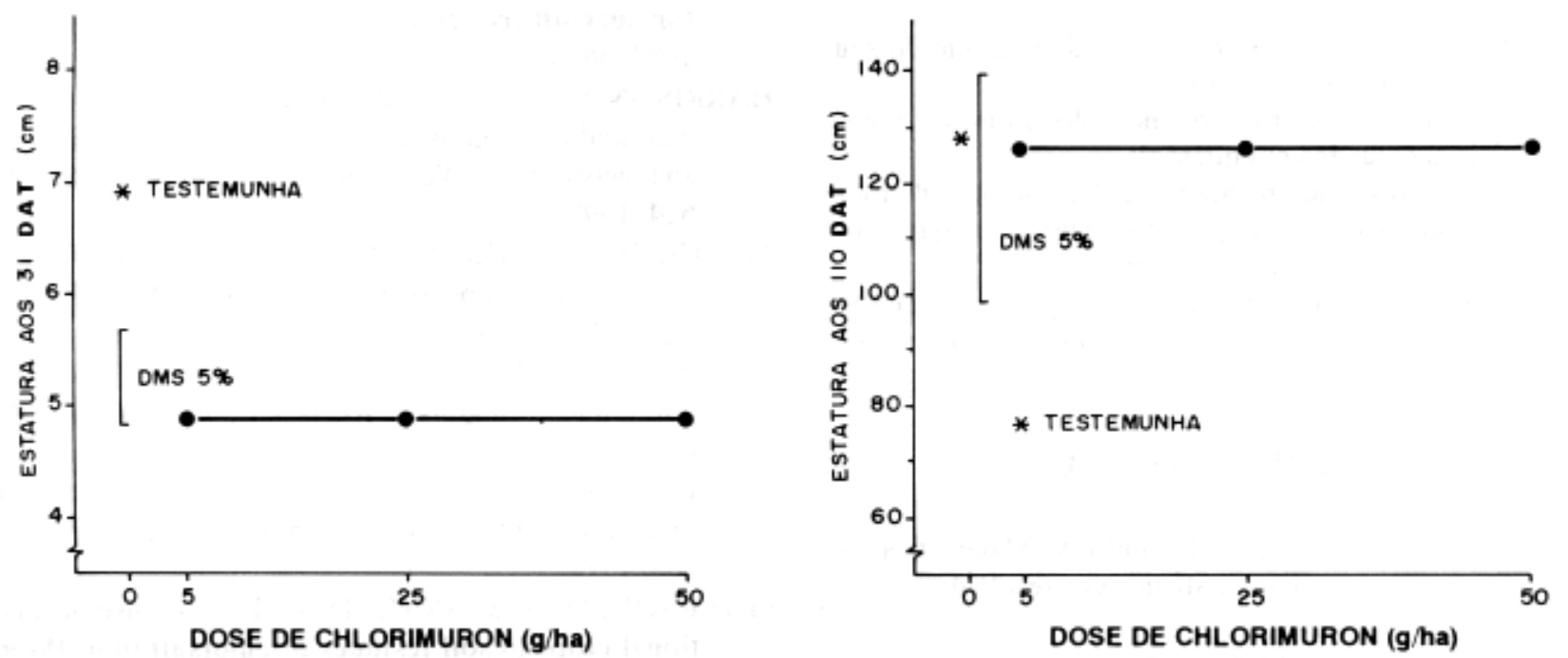

FIG. 2. Estatura das plantas de girassol aos 31 e 110 dias após aspersão ao solo do herbicida chlorimuron (média das aplicaçōes em PRE e PPI), comparadas à testemunha sem herbicida. EEA/UFRS, Eldorado do Sul, RS, $1989 / 90$.

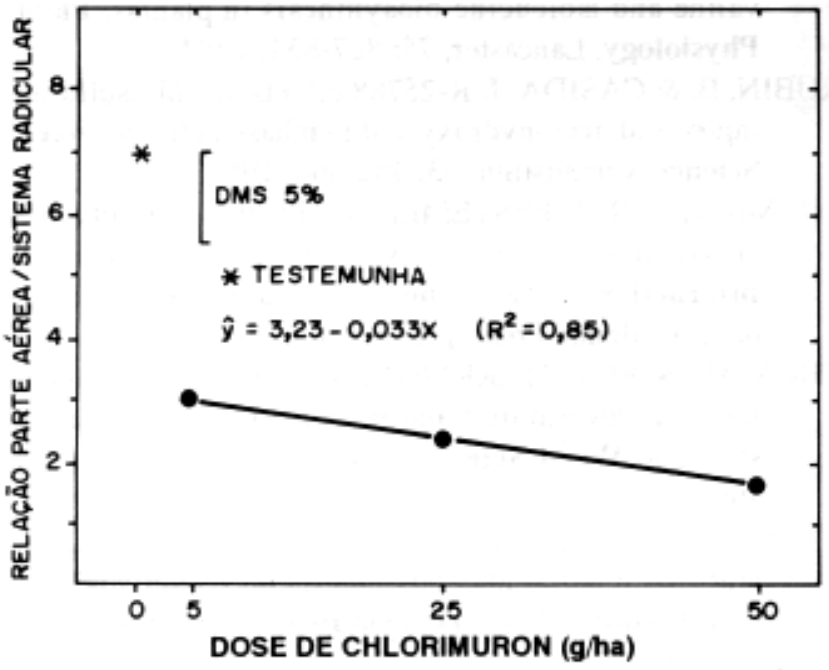

FIG. 3. Relaçâo parte aérea/sistema radicular das plantas de girassol aos $\mathbf{3 1}$ dias após aspersão ao solo do herbicida chlorimuron (média das aplicaçóes em PRE e PPI), comparadas à testemunha sem herbicida. EEA/UFRS, Eldorado do Sul, RS, 1989/90.

síveis para este fato, sugeridas por Rubin \& Casida (1985) e por Mazur \& Falco (1989), são: menor atividade da enzima ALS no sistema radicular; ocorrência de enzimas menos sensíveis a este composto nas raízes; ou, maior destoxificação das moléculas do herbicida no sistema radicular.

Para se estimar o efeito residual potencial deste herbicida ao girassol deve-se considerar que chlorimuron é recomendado para aplicação em pós-emergência da cultura da soja, na dose de $20 \mathrm{~g} / \mathrm{ha}$. Admitindo-se que toda esta dose atingisse o solo e considerando $5 \mathrm{~g} / \mathrm{h}$ a como a dose necessária para reduzir a matéria seca das plântulas de girassol em $61 \%$ (Figura 1), pode-se estimar a constante de degradação (k) através da equação a seguir (1):

$$
\operatorname{Ln}([\mathrm{Cf}] /[\mathrm{Ci}])=-\mathrm{k} \mathrm{t}
$$

Esta equação, de acordo com Bechie \& Mckercher (1989), representa a cinética da degradação de chlorimuron no solo; onde [Ci] e [Cf] são as concentrações do herbicida no tempo inicial e final, respectivamente; $\mathrm{k}$ é a constante de degradação; e t é o tempo, o qual pode-se considerar 210 dias, uma vez que este é o período médio entre aplicação de chlorimuron na cultura da soja e semeadura do girassol. Assim, o valor -k obtido a partir dos dados acima corresponde a 0,0066. A partir deste valor pode-se estimar a meiavida do herbicida (t 1/2) utilizando-se a equação (2):

$$
\mathrm{t} 1 / 2=0,693 / \mathrm{k}
$$

Para que houvesse redução de $61 \%$ na matéria seca das plantas de girassol aos 30 dias após a semeadura, a meia-vida deveria ser 105 dias. Contudo, comparando-se as avaliações de estatura realizadas aos 31 e 110 DAT (Figura 2), pode-se verificar que ocorreu recuperação das plantas quanto aos danos promovidos pelo herbicida. Resultados semelhantes foram obtidos por Eberlein et al. (1989), que constataram recuperação dos sintomas de fitotoxicidade promovidos por uma sulfoniluréia a diversos genótipos de milho, entre as avaliações realizadas 2 e 4 semanas após aplicação do produto. Investigando as causas deste comportamento, os autores constataram a ocorrência de metabolização da molécula pelo vegetal. Esta metabolização foi elucidada por Beyer et al. (1988) que, trabalhando com chlorimuron, constataram que o composto é degradado no interior das plantas de soja e de outras espécies num mecanismo semelhante ao da degradação de acifluorfen e metribuzin. Estes compostos são conjugados com a homoglutationa (um tripeptídeo formado por glutamato, cisteína e alanina), perdendo seu efeito herbicida. Resultados obtidos por Vidal \& Fleck (1992) também indicaram recuperação parcial do girassol quando aspergido por chlorimuron no estádio de 10 folhas. Estes dados sugerem que as plantas de girassol também apresentam um mecanismo de destoxificação deste herbicida. Contudo, esta especulação precisa ser demonstrada com maiores evidências. 
Os resultados obtidos neste experimento permitem concluir que:

» a atividade de chlorimuron não é dependente do seu método de aplicação ao solo;

» a presença de chlorimuron no solo promove danos iniciais acentuados em girassol;

》 o girassol apresenta recuperação dos sintomas de fitotoxicidade ocasionados por chlorimuron, os quais diminuem com o decorrer do tempo;

» aparentemente, num sistema de rotação soja-girassol, o efeito residual potencial de chlorimuron ao girassol é pequeno.

\section{AGRADECIMENTOS}

Ao Dr. João Riboldi, do Instituto de Matemática da UFRS, pelo apoio na análise estatística dos resultados.

\section{LITERATURA CITADA}

BECKIE, H. J. \& MCKERCHER, R. B. Soil residual properties of DPX-A7881 under laboratory conditions. Weed Science, Champaign, 37: 412-418, 1989.

BEYER, E. M.; DUFFY, M. J.; HAY, J. V. \& SCHLUETER, D. D. Sulfonylurea In: KEARNEY, P.C. \& KAUFMAN, D. D. eds. Herbicides: chemistry, degradation, and mode of action. New York, M. Dekker. 1988.3: 117-189.

BREWSTER, B. D. \& APPLEBY, A. P. Response of wheat (Triticum aestivum) and rotation crops to chlorsulfuron. Weed Science, Champaign, 31: 861-865,1983.

CHEW, V. Comparing treatment means: a compendium. HortScience, Alexandria, 11: 348-357, 1976.

CURRAN, W. S. \& KNAKE, E. L. Rotational crop injury potential for corn following clomazone, imazaquin, imazethapyr and chlorimuron in Illinois. In: MAINZ, M. J. \& SUTOR, J. J. Northwestern Illinois Agricultural Research and Demonstration Center, Report of Research Results. Urbana-Champaign, Univ. of Illinois. 1987. p.114-119.

EBERLEIN, C. V.; ROSOW, K. M.; GEADELMANN, J. L. \& OPENSHAW, S. J. Differential tolerance of corn genotypes to DPX-M63133. Weed Science, Champaign, 37: 651-657, 1989.

GOETZ, A. J.; WALKER, R. H.; WEHTJE, G. \& HAJEK, B. F. Sorption and mobility of clorimuron in Alabama soils. Weed Science, Champaign, 37: 428-433, 1989.
GOMEZ, K. A. \& GOMEZ, A. O. Statistical procedures for agricultural research. 2.ed. New York, Wiley, 1984. 680p.

HARRISON, S. K. \& THOMAS, S. M. Interaction of surfactants and reaction media on photolysis of chlorimuron and metsulfuron. Weed Science, Champaign, 38: 620624, 1990.

MAZUR, B. J. \& FALCO, S. C. The development of herbicide resistent crops. Annual review of Plant Physiology, Palo Alto, 40: 441-470, 1989.

NOGUEIRA, I. R. Método geral para obtenção de tabelas de polinômios ortogonais. Revista de Agricultura, Piracicaba, 53: 269-279, 1979.

PETERSEN, R. G. Use and misuse of multiple comparison procedures. Agronomy Journal, Madison, 69: 205$208,1977$.

PETERSON, M. A. \& ARNOLD, W. E. Response of rotational crops to soil residues of chlorsulfuron. Weed Science, Champaign, 34: 131-136, 1985.

RAY, T. B. Site of action of chlorsulfuron; inhibition of valine and isoleucine biosynthesis in plantas. Plant Physiology, Lancaster, 75: 827-831, 1984.

RUBIN, B. \& CASIDA, J. R-25788 effects on chlorsulfuron injury and acetohydroxyacid synthase activity. Weed Science, Champaign, 33: 462-468, 1985.

SCHMIDT, R. R. \& PESTEMER, W. Plant availability and uptake of herbicides from soils. In: HANCE, R. J. ed. Interactions between herbicides and the soil. London, Academic Press. p.179-201. 1980.

THOMAS, S. M. \& HARRISON, S. K. Surfactant-altered rates of chlorimuron and metsulfuron photolysis in sunlight. Weed Science, Champaign, 38: 602-606, 1990.

VIDAL, R. A. \& FLECK N. G. Controle de girassol espontâneo com herbicidas pós-emergentes seletivos para soja. Pesquisa Agropecuaria Brasileira, Brasilia, 27: 549-560, 1992.

VIDAL, R. A. \& FLECK N. G. Injuria potencial de herbicidas de solo ao girassol. I - Clomazone. Planta Daninha, Brasília, 11: 36-43. 1993.

WESLEY, R. A.; SHAW, D. R. \& BARRENTINE, W. L. Incorporation depths of imazaquin, metribuzin, and chlorimuron for common cocklebur (Xanthium strumarium) control in soybeans (Glycine max). Weed Science, Champaign, 37: 596-599, 1989. 